\title{
MODELO DE PROGRAMAÇÃO LINEAR PARA SELEÇÃO DE DIFERENTES FORMAS DE PULVERIZAÇÃO AGRÍCOLA PARA CANA-DE-AÇÚCAR
}

\author{
Ródney Ferreira Couto ${ }^{1}$, João Paulo Barreto Cunha ${ }^{2}$, Elton Fialho dos Reis ${ }^{3}$
}

\begin{abstract}
RESUMO
$\mathrm{O}$ engenheiro que exerce atividades na agricultura, muitas vezes, se defronta com o problema de projetar um sistema mecanizado, para uma dada operação, como por exemplo, a aplicação de agroquímicos em cana-de-açúcar. O objetivo do presente trabalho foi o de desenvolver e utilizar um modelo de programação linear para auxilio no processo de seleção das diferentes formas de pulverização agrícola utilizadas na cultura da cana-de-açúcar, baseado no menor custo horário dos equipamentos. Foram utilizadas informações técnicas referentes às três formas de aplicação utilizadas na referida cultura, podendo ser realizadas com pulverizadores de arrasto, autopropelidos e por meio de aplicações aéreas. As análises de sensibilidade para o custo horário com variação da área total da usina, da área a ser reformada, da área a ser tratada com inseticida sistêmico e do tempo total disponível para cada aplicação, demonstraram que a utilização de pulverizadores autopropelidos e aviões são as formas de pulverização que proporcionam menores custos horários obedecendo todas as restrições. O modelo matemático desenvolvido facilitou a realização da análise de sensibilidade que foi processada em um tempo pequeno.
\end{abstract}

Palavras-chave: agroquímicos, máquinas agrícolas, programação linear

\section{LINEAR PROGRAMMING MODEL FOR SELECTION OF DIFFERENT FORMS FOR AGRICULTURAL SPRAYING IN SUGAR CANE}

\begin{abstract}
The engineer who performs activities in agriculture, often, faces the problem of designing a mechanized system for a given operation, for example, application of pesticides from cane sugar. The objective of this study was to develop and use a linear programming model to aid in the selection of different forms of agricultural spray used in the culture of sugar cane, on the lowest hourly cost of equipment. It was used technical information for the three application methods used in such cultivation. It can be achieved with drag sprays, by self-propelled and aerial applications. Sensitivity analysis per hourly cost with the variation of the total area, the area to be reformed, the area to be treated with systemic insecticide and the total time available for each application, demonstrated that the use of self-propelled sprayers and airplanes are spray forms that provide lower cost schedules obeying all restrictions. The developed mathematical model facilitated the implementation of sensitivity analysis that was processed in a short time.
\end{abstract}

Keywords: agricultural chemicals, agricultural machines, linear programming

Recebido para publicação em 21/06/2012. Aprovado em 19/09/2012.

1- Engenheiro Agrícola, Prof. Msc. da UNUCET/UEG, Anápolis - GO, rodneycouto@agricola.eng.br

2- Engenheiro Agrícola, Doutorando em Eng. Agrícola DEG/UFLA, Lavras - MG, bcunha@posgrad.ufla.br

3- Eng. Agrícola, Prof. Dsc. da UNUCET/UEG, Anápolis-GO, fialhoreis@ueg.br 


\section{INTRODUÇÂO}

O setor agrícola brasileiro caminha a passos largos para a modernização, pois atualmente o mercado agrícola tem grande influência e competição de empresas estrangeiras que oferecem qualidade em seus produtos, quantidade e preços mais baixos. Até o inicio da década de 80 a agricultura brasileira, por contar com privilégios governamentais, produzia para consumo e venda sem preocupação com planejamento e racionalização das atividades dentro e fora da propriedade (CALVAZARA, 1999).

Menezes \& Pinheiro (2004) citam que a complexidade que permeia o setor agrícola envolvendo componentes econômicos, financeiros, sociais e ambientais torna a tomada de decisões um processo que envolve etapas a serem cumpridas, as quais transcendem a otimização de um objetivo, de forma pontual e isolada.

Dentro desse contexto, segundo Mercante et al. (2010), a mecanização agrícola está em fluxo continuo de desenvolvimento e a utilização de novas tecnologias vem exigindo o uso racional, objetivando não só maior rendimento e produção, mas também a redução dos gastos. A seleção adequada de uma máquina agrícola como de um implemento pode tornar-se uma tarefa árdua devido as inúmeras variáveis a serem consideradas (BAIO et al., 2004).

Segundo Biembegut \& Hein (2005) a modelagem matemática é o processo que envolve a obtenção de um modelo, formulando, resolvendo e elaborando expressões que possibilitem um suporte para diversas aplicações. Para Caixeta Filho (2001) um modelo matemático é uma estrutura que permite representar a realidade de maneira simplificada obtendo uma solução ótima, ou seja, a solução viável mais favorável para a função-objetivo.

Hoffmann et al. (1984) referem-se à programação linear como método de planejamento aplicada em estudos visando auxiliar na tomada de decisões e na programação de ações a serem executadas para maximizar ou minimizar determinado objetivo. Segundo Williams (1993), em um problema de programação linear geralmente algumas soluções são viáveis quando se satisfaz todas as restrições, havendo, no entanto, apenas uma solução ótima. No caso de seleção de máquinas e equipamentos agrícolas a solução faz sentido somente se as variáveis de decisão possuírem valores inteiros.

Otimizando um sistema agrícola visando à maximização do lucro, Fey et al. (2002) utilizaram um modelo de programação linear onde foram consideradas algumas restrições como área, rotação de culturas, recursos financeiros e maquinário agrícola disponível. A resolução do modelo possibilitou um aumento no lucro em $9,8 \%$.

Com o objetivo de desenvolver e utilizar um modelo de programação linear para auxiliar na seleção de pulverizadores agrícolas de barras, Baio et al. (2004) basearam-se no menor custo horário do equipamento. De acordo com os autores, a análise de sensibilidade dos componentes dos custos operacionais mostrou que as taxas de reparo e de depreciação foram os fatores que mais influenciaram na variação do custo horário dos conjuntos avaliados. O modelo utilizado, além de facilitar a realização da analise de sensibilidade, permitiu a otimização da funçãoobjetivo, auxiliando de maneira efetiva na seleção de pulverizadores agrícolas com base no menor custo horário.

Objetivou-se, com o presente estudo, desenvolver e utilizar um modelo de programação linear inteira para auxilio no processo de seleção entre as várias formas de pulverização agrícola utilizada na cultura da cana-de-açúcar, baseado no menor custo horário dos equipamentos.

\section{MATERIAL E MÉTODOS}

Foi desenvolvido um modelo de programação linear inteiro para o auxilio no processo de seleção entre os vários tipos de pulverização agrícola. Para aplicação do modelo, consideraram-se as áreas agrícolas de uma usina sucroalcooleira, situada na região de Goianésia - GO, que cultiva 30.000 ha de cana-de-açúcar (Saccharum officinarum L.). Foi considerado que a usina realiza aplicações de dessecante (MSMA), pós-emergente (Amicarbazone), herbicida de seca (Tebutiurom), inseticida sistêmico (Tiametoxame), maturadores 
(Sulfometuron metil) e inibidores (Trinexapaqueetílico) durante a safra.

Dentre todas as operações, a reforma do canavial é realizada durante a safra em $17 \%$ da área total, ou seja, em 5.000 ha. A aplicação de herbicida de seca também é realizada durante a safra, correspondendo a $83 \%$ da área total, ou seja, em 25.000 ha. Para a aplicação de inseticida sistêmico, devido ao seu elevado custo, a área destinada para essa aplicação é de $48 \%$ de 25.000 há, correspondendo à 12.000 ha. As aplicações áreas somente ocorrem para maturadores $\mathrm{e}$ inibidores, perfazendo um total de 6.000 ha para os maturadores e 10.000 ha para os inibidores.

Para as operações de reforma do canavial, aplicações de herbicida de seca, inseticida sistêmico, maturadores e inibidores considerouse um tempo disponível de: 140, 150, 60, 10 e 15 dias, respectivamente. Considerou-se dois turnos de trabalho de oito horas por dia.

O modelo de programação linear desenvolvido avaliou os diferentes tratamentos fitossanitários e também as três formas de pulverização agrícola utilizadas no processo produtivo da usina, que são realizadas por meio de pulverizadores de arrasto, por meio de pulverizadores autopropelidos e, por último, utilizando aviação agrícola (Quadro 1).

Por meio de consulta nos manuais dos fabricantes obteve-se a largura nominal de trabalho, a capacidade do tanque, a velocidade de trabalho e/ou vôo e o tipo de cada modelo de equipamento.

Os pulverizadores foram orçados em revendas especializadas e para o avião agrícola o seu preço foi obtido por consulta direta com o fabricante da aeronave. A capacidade de campo operacional foi calculada a partir dos dados dimensionais de cada pulverizador e das estimativas de eficiência de pulverização apresentadas por ASAE (1998).
No caso da aplicação aeroagrícola, o rendimento $(\mathrm{ha} / \mathrm{h})$ foi determinado utilizando a metodologia descrita por Araújo (1976), que é uma variação da Fórmula de Baltin (BALTIN, 1959). Por essa razão foi suprimida toda a rotina de cálculos para a obtenção da capacidade de campo operacional do sistema de pulverização com aviação agrícola.

Para a implantação do modelo, foi necessário a realização de alguns cálculos preliminares à otimização, subdivididos em três etapas: cálculo do ritmo operacional do plano de produção da empresa agrícola; da capacidade de campo efetiva e dos custos fixos e variáveis dos equipamentos. Consideraram-se os custos fixos e operacionais do pulverizador autopropelido, do pulverizador de arrasto e do trator agrícola, entretanto para a aviação agrícola, os custos foram fornecidos pela empresa terceirizada que presta serviço junto à usina.

Os custos fixos foram definidos como aqueles que não variam em relação à taxa de produção. São despesas contraídas da posse de algum bem e não são influenciados pela quantidade de utilização do mesmo, sendo inclusas as seguintes despesas: depreciação, alojamento, seguro, reparo anual e mão-de-obra. Os custos variáveis dizem respeito aos dispêndios com fatores de produção variáveis. Para a obtenção do custo operacional, foram incluídas as taxas de reparo e de manutenção, custos com combustível, óleo lubrificante, graxa e operador (BALASTREIRE, 1990).

Os custos referentes ao trator agrícola foram considerados e somados aos custos referentes ao pulverizador de arrasto. Foram inclusos os custos referentes a um trator agrícola de 91,9 kW (125 cv) de potência capaz de manter em operação o pulverizador de arrasto. Considerou-se o valor de compra desse trator de R $\$ 120.000,00$.

Quadro 1. Tipo de pulverizador, preço, largura efetiva, capacidade de campo efetiva e capacidade do tanque

\begin{tabular}{lcccc}
\hline $\begin{array}{c}\text { Tipo de Pulverizador } / \\
\text { Pulverização }\end{array}$ & $\begin{array}{c}\text { Preço } \\
(\mathrm{R} \$)\end{array}$ & $\begin{array}{c}\text { Largura Efetiva / } \\
\text { Largura de faixa } \\
(\mathrm{m})\end{array}$ & $\begin{array}{c}\text { Capacidade de } \\
\text { Campo Efetiva } \\
\left(\mathrm{ha} \mathrm{h}^{-1}\right)\end{array}$ & $\begin{array}{c}\text { Capacidade do } \\
\text { Tanque } \\
(\mathrm{L})\end{array}$ \\
\hline Arrasto & $70.000,00$ & 14 & 8,33 & 1500 \\
Autopropelido & $450.000,00$ & 22 & 22,44 & 2000 \\
Aérea & $654.000,00$ & 20 & 115,48 & 600 \\
\hline
\end{tabular}


$\mathrm{Na}$ Figura 1 tem-se uma representação esquemática da sequência de cálculos para o ritmo operacional, conforme Baio et al. (2004).

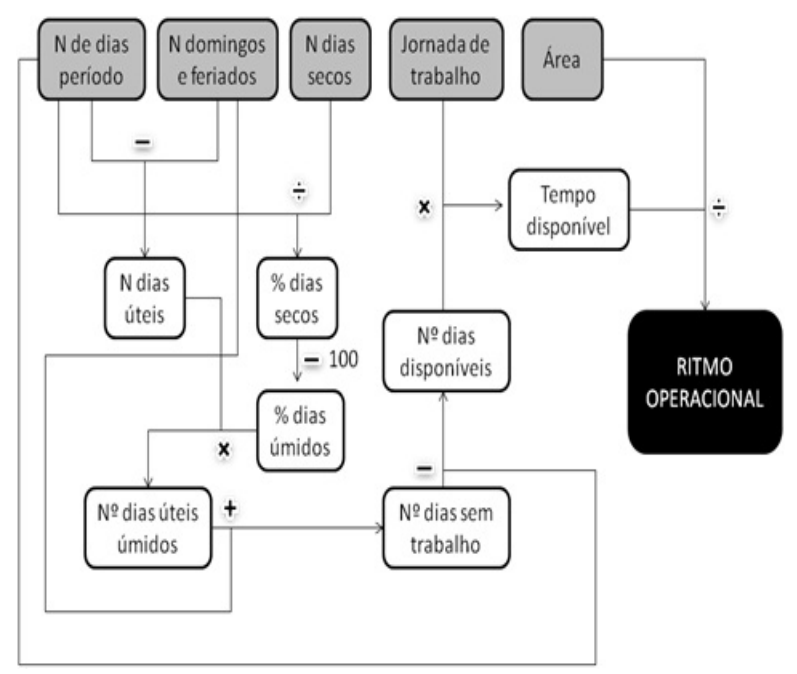

Figura 1. Representação esquemática da sequência de cálculos para o ritmo operacional.

Na Figura 2, ilustra-se a sequência de cálculos para obtenção do custo operacional do conjunto trator - pulverizador de arrasto e segue o raciocínio dos autores citados anteriormente.

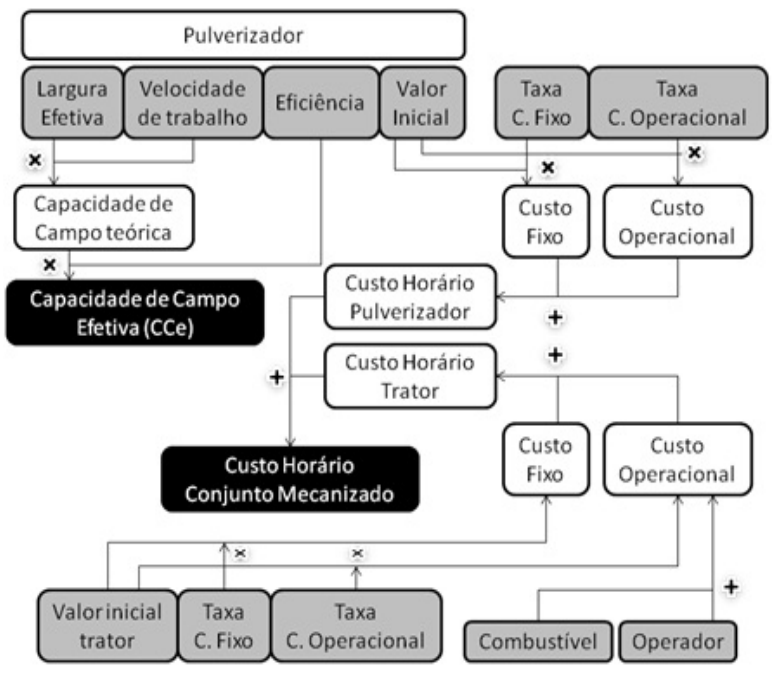

Figura 2. Representação esquemática da sequência de cálculosparaa definição do custo operacional do conjunto trator - pulverizador.

A Figura 3 apresenta o fluxograma para a situação envolvendo pulverização com modelos autopropelidos.

O modelo de programação linear proposto foi processado por um computador Intel Pentium Dual
Core de $2.4 \mathrm{GHz}$, com 2 GB de memória RAM. Foi utilizado o aplicativo Solver do Excel 2007 que trabalha com programação linear inteira.

Utilizou-se o custo horário como fator de minimização no modelo, pois esse foi calculado baseado em todos os custos fixos e operacionais. No entanto, também foram calculados os custos por unidade de área (MIALHE, 1974) para fins comparativos.

Foram realizadas análises de sensibilidade para o custo horário com variação da área total da usina, da área a ser reformada, da área a ser tratada com inseticida sistêmico e do tempo total disponível para cada aplicação.

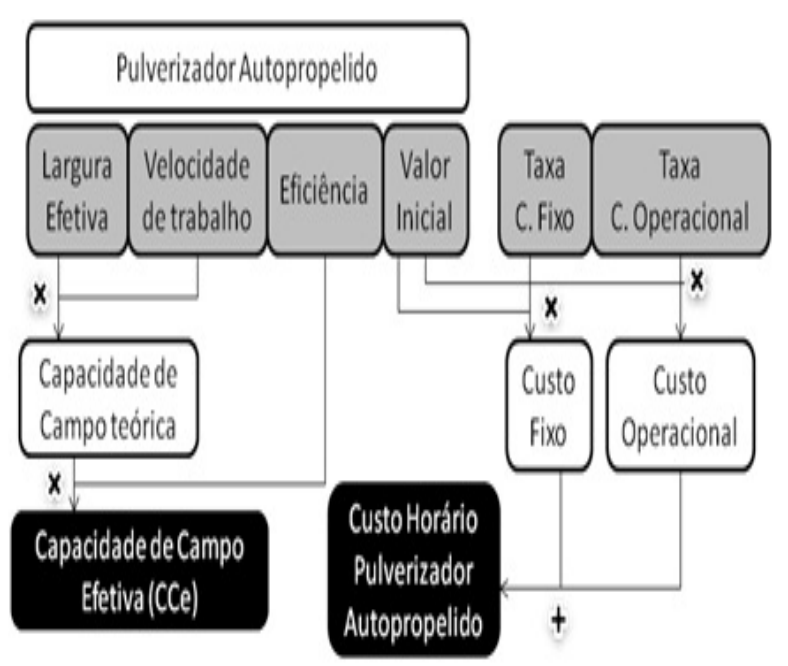

Figura 3. Representação esquemática da sequência de cálculos para a definição do custo operacional do pulverizador autopropelido.

\section{RESULTADOS E DISCUSSÃO}

O modelo matemático desenvolvido para o auxílio na tomada de decisão entre as diversas formas de pulverização agrícola, com base no menor custo horário, foi:

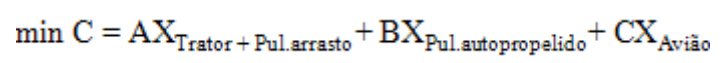

em que

$\mathrm{C}=$ Custo horário, $\mathrm{R} \$ \mathrm{~h}^{-1}$;

$\mathrm{A}=$ Custo horário total do conjunto trator + pulverizador de arrasto, $\mathrm{R} \$ \mathrm{~h}^{-1}$; 


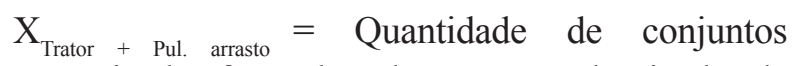
mecanizados formado pelo trator + pulverizador de arrasto, unidades;

$\mathrm{B}=$ Custo horário total do pulverizador autopropelido, $\mathrm{R} \$ \mathrm{~h}^{-1}$;

$\mathrm{X}_{\text {Pul. autopropelido }}=$ Quantidade de pulverizadores autopropelidos, unidades;

$\mathrm{C}=$ Custo horário da aviação, $\mathrm{R} \$ \mathrm{~h}^{-1}$; e

$\mathrm{X}_{\text {Avião }}=$ Quantidade de aviões, unidades.

As restrições impostas ao modelo foram:

*Número mínimo de conjuntos selecionados:

$\mathrm{X}_{\text {Trator + Pul. arrasto }}+\mathrm{X}_{\text {Pul. autopropelido }}+\mathrm{X}_{\text {Avião }} \geq 1$

*Número máximo de operadores:

$\mathrm{X}_{\text {Trator }+ \text { Pul. arrasto }}+\mathrm{X}_{\text {Pul. autopropelido }} \leq 4$

* Número máximo de pilotos:

$\mathrm{X}_{\text {Avião }} \leq 2$

*Dessecante (Reforma do Canavial):

$\mathrm{CCe}_{\text {Trator + Pul. arrasto }} \mathrm{X}_{\text {Trator + Pul. arrasto }}+\mathrm{CCe}_{\text {Pul. autopropelido }} \mathrm{X}_{\text {Pul. }}$ autopropelido $\geq \mathrm{RO}_{\text {Dessecação }}$

* Pós-emergente (Reforma do Canavial):

$\mathrm{CCe}_{\text {Trator }+ \text { Pul. arrasto }} \mathrm{X}_{\text {Trator + Pul. arrasto }}+\mathrm{CCe}_{\text {Pul. autopropelido }} \mathrm{X}_{\text {Pul. }}$ autopropelido $\geq \mathrm{RO}_{\text {Pós-Emergente }}$

* Herbicida de Seca:

$\mathrm{CCe}_{\text {Trator + Pul. arrasto }} \mathrm{X}_{\text {Trator + Pul. arrasto }}+\mathrm{CCe}_{\text {Pul. autopropelido }} \mathrm{X}_{\text {Pul. }}$ autopropelido $\geq \mathrm{RO}_{\text {Herbicida de Seca }}$

* Inseticida Sistêmico:

$\mathrm{CCe}_{\text {Pul. autopropelido }} \mathrm{X}_{\text {Pul. autopropelido }} \geq \mathrm{RO}_{\text {Inseticida Sistêmico }}$
* Maturadores:

$\mathrm{CCe}_{\text {Avião }} \mathrm{X}_{\text {Avião }} \geq \mathrm{RO}_{\text {Maturadores }}$

* Inibidores:

$\mathrm{CCe}_{\text {Avião }} \mathrm{X}_{\text {Avião }} \geq \mathrm{RO}_{\text {Inibidores }}$

A solução gerada pelo programa foi considerada ótima, significando que a função-objetivo pôde ser minimizada. O sistema resolveu o problema em 11,97 s. O valor da função-objetivo encontrado foi de $\mathrm{R} \$ 2.804,6 \mathrm{~h}^{-1}$. O custo por unidade de área para os conjuntos selecionados foi de $\mathrm{R} \$ 29,99 \mathrm{ha}^{-1}$. Para atingir esse valor, foram selecionadas duas formas de pulverização: pulverizador autopropelido e aviação agrícola. O pulverizador autopropelido selecionado apresenta uma capacidade de tanque de 2000 L e uma largura de barra de 22 m e o avião agrícola possui capacidade de carga de $600 \mathrm{~L}$ e largura de faixa de $20 \mathrm{~m}$.

$\mathrm{O}$ relaxamento da restrição do número máximo de operadores e pilotos não mudou a solução ótima para o problema. A restrição do número máximo de operadores e pilotos apresentou folga, não sendo uma restrição atuante.

O Quadro 2 apresenta a análise de sensibilidade para o custo horário devido ao aumento da área total da usina. Considerou-se um incremento anual de 5.000 ha respeitando as proporções de área destinada a cada operação de aplicação, descritas anteriormente.

$\mathrm{O}$ incremento de 5000 ha em relação à área inicial fez com que o modelo selecionasse dois aviões. O mesmo comportamento foi obtido para o aumento gradual da área até 50.000 ha. Deste ponto em diante, o modelo selecionou o dobro do número de conjuntos obtidos para a condição inicial.

Quadro 2. Análise de sensibilidade para o custo horário devido ao aumento anual da área total da usina

\begin{tabular}{|c|c|c|c|c|c|c|}
\hline Ano & $\begin{array}{c}\text { Área } \\
\text { (ha) }\end{array}$ & $\begin{array}{c}\text { Ritmo } \\
\text { Operacional da } \\
\text { Usina }\left(\mathrm{ha} \mathrm{h}^{-1}\right)\end{array}$ & $\begin{array}{l}\text { Tipo de Pulverizador } \\
\text { Selecionado }\end{array}$ & $\begin{array}{l}\text { Número de } \\
\text { Conjuntos }\end{array}$ & $\begin{array}{l}\text { Custo } \\
\text { Horário } \\
\left(\mathrm{R} \$ \mathrm{~h}^{-1}\right)\end{array}$ & $\begin{array}{c}\text { Custo por } \\
\text { Área total } \\
\left(\mathrm{R} \$ \mathrm{ha}^{-1}\right)\end{array}$ \\
\hline 0 & 30000 & 242,96 & Autopropelido + Avião & 1,1 & 2804,86 & 29,99 \\
\hline 1 & 35000 & 282,25 & Autopropelido + Avião & 1,2 & 5518,64 & 56,30 \\
\hline 2 & 40000 & 322,57 & Autopropelido + Avião & 1,2 & 5518,64 & 56,41 \\
\hline 3 & 45000 & 362,89 & Autopropelido + Avião & 1,2 & 5518,64 & 56,18 \\
\hline 4 & 50000 & 403,22 & Autopropelido + Avião & 1,2 & 5518,64 & 55,99 \\
\hline 5 & 55000 & 443,54 & Autopropelido + Avião & 2,2 & 5609,72 & 57,39 \\
\hline 6 & 60000 & 483,86 & Autopropelido + Avião & 2,2 & 5609,72 & 57,13 \\
\hline
\end{tabular}


A análise de sensibilidade para o custo horário devido à variação da área a ser reformada, em relação à área total inicial é apresentada no Quadro 3. De acordo com os resultados obtidos é possível verificar que somente acima de 23000 ha é que o modelo selecionou as três formas de pulverização. Como é inviável reformar praticamente toda a área da usina de uma única vez, esse resultado é apenas para fins de simulação. Com o incremento da área a ser reformada, até 23.000 ha, o custo horário permaneceu constante devido ao tipo de pulverizador selecionado e o número de conjuntos permanecerem inalterado. Entretanto, o custo por unidade de área é reduzido com o aumento da área. Isso pode ser explicado pelo fato dos equipamentos trabalharem mais próximos de sua capacidade operacional, ou seja, tem-se uma redução na ociosidade dos equipamentos.

De acordo com os resultados apresentados no Quadro 4 é possível verificar que a usina pode aumentar as áreas a serem tratadas com inseticida sistêmico até 21000 ha, utilizando os mesmos equipamentos, sem a necessidade de adquirir novos conjuntos. Com relação aos custos têmse comportamento semelhante ao apresentado no Quadro 3. O modelo verificou a necessidade de adicionar outro pulverizador autopropelido, somente quando a área a ser tratada com este produto aumentou para 24000 ha.

No Quadro 5 é apresentada a análise de sensibilidade para o custo horário devido às reduções de 25 e $50 \%$ do tempo total disponível para as operações de pulverização da usina. Verificouse que, ao reduzir o tempo total disponível para todas as operações em $25 \%$, o modelo selecionou outra aeronave devido ao aumento dos ritmos operacionais, principalmente dos tratamentos envolvendo maturadores e inibidores. Uma redução de $50 \%$ do tempo total fez com que o modelo selecionasse dois pulverizadores autopropelidos e dois aviões. Pode-se observar que o custo horário dobrou quando o tempo disponível foi reduzido pela metade, pois o modelo dobrou o número de conjuntos mecanizados para atender ao ritmo operacional máximo no período.

Quadro 3. Análise de sensibilidade para o custo horário devido à variação de $10 \%$ da área a ser reformada (dessecante e pós-emergente) em relação à área total inicial

\begin{tabular}{cccccc}
\hline $\begin{array}{c}\text { Área } \\
\text { (ha) }\end{array}$ & $\begin{array}{c}\text { Ritmo Operacional } \\
\text { da Usina }\left(\text { ha h }^{-1}\right)\end{array}$ & $\begin{array}{c}\text { Tipo de Pulverizador } \\
\text { Selecionado }\end{array}$ & $\begin{array}{c}\text { Número de } \\
\text { Pulverizadores }\end{array}$ & $\begin{array}{c}\text { Custo } \\
\text { Horário } \\
\left(\mathrm{R} \$ \mathrm{~h}^{-1}\right)\end{array}$ & $\begin{array}{c}\text { Custo por } \\
\text { Área total } \\
\left(\mathrm{R} \$ \text { ha }^{-1}\right)\end{array}$ \\
\hline 5000 & 242,96 & Autopropelido + Avião & 1,1 & 2804,86 & 29,99 \\
8000 & 248,31 & Autopropelido + Avião & 1,1 & 2804,86 & 29,58 \\
11000 & 253,67 & Autopropelido + Avião & 1,1 & 2804,86 & 29,28 \\
14000 & 259,03 & Autopropelido + Avião & 1,1 & 2804,86 & 29,04 \\
17000 & 264,38 & Autopropelido + Avião & 1,1 & 2804,86 & 28,85 \\
20000 & 269,74 & Autopropelido + Avião & 1,1 & 2804,86 & 28,69 \\
23000 & 275,10 & Autopropelido + Avião & 1,1 & 2804,86 & 28,56 \\
26000 & 280,45 & Arrasto + Autopropelido + Avião & $1,1,1$ & 2881,30 & 35,79 \\
\hline
\end{tabular}

Quadro 4. Análise de sensibilidade para o custo horário devido à variação da área a ser tratada com inseticida sistêmico com incrementos de $10 \%$

\begin{tabular}{cccccc}
\hline $\begin{array}{c}\text { Área } \\
(\text { ha })\end{array}$ & $\begin{array}{c}\text { Ritmo Operacional da } \\
\text { Usina } \\
\left(\mathrm{ha} \mathrm{h}^{-1}\right)\end{array}$ & $\begin{array}{c}\text { Tipo de Pulverizador } \\
\text { Selecionado }\end{array}$ & $\begin{array}{c}\text { Número de } \\
\text { Pulverizadores }\end{array}$ & $\begin{array}{c}\text { Custo } \\
\text { Horário } \\
\left(\mathrm{R} \$ \mathrm{~h}^{-1}\right)\end{array}$ & $\begin{array}{c}\text { Custo por } \\
\text { Área total } \\
\left(\mathrm{R} \$ \text { ha }^{-1}\right)\end{array}$ \\
\hline 12000 & 242,96 & Autopropelido + Avião & 1,1 & 2804,86 & 29,99 \\
15000 & 246,08 & Autopropelido + Avião & 1,1 & 2804,86 & 29,74 \\
18000 & 249,21 & Autopropelido + Avião & 1,1 & 2804,86 & 29,53 \\
21000 & 252,33 & Autopropelido + Avião & 1,1 & 2804,86 & 29,35 \\
24000 & 255,46 & Autopropelido + Avião & 2,1 & 2895,94 & 31,24 \\
\hline
\end{tabular}

534 REVENG 
Quadro 5. Análise de sensibilidade para o custo horário devido às reduções de 25 e $50 \%$ do tempo total disponível para as operações de pulverização

\begin{tabular}{lccccc}
\hline $\begin{array}{c}\text { Tempo total } \\
\text { disponível* } \\
\text { (dias) }(\%)\end{array}$ & $\begin{array}{c}\text { Ritmo Operacional } \\
\left(\mathrm{ha} \mathrm{h}^{-1}\right)\end{array}$ & $\begin{array}{c}\text { Tipo de Pulverizador } \\
\text { Selecionado }\end{array}$ & $\begin{array}{c}\text { Número de } \\
\text { Conjuntos }\end{array}$ & $\begin{array}{c}\text { Custo } \\
\text { Horário } \\
\left(\mathrm{R} \$ \mathrm{~h}^{-1}\right)\end{array}$ & $\begin{array}{c}\text { Custo por } \\
\text { Área } \\
\left(\mathrm{R} \$ \mathrm{ha}^{-1}\right)\end{array}$ \\
\hline $375(100)$ & 242,96 & Autopropelido + Avião & 1,1 & 2804,86 & 29,99 \\
$279(25)$ & 337,01 & Autopropelido + Avião & 1,2 & 5518,64 & 56,41 \\
$187(50)$ & 485,91 & Autopropelido + Avião & 2,2 & 5609,72 & 55,70 \\
\hline
\end{tabular}

* Na composição do tempo total disponível tem-se a somatória dos tempos disponibilizados para cada operação. Entretanto, algumas operações podem ser feitas simultaneamente, como por exemplo, aplicação de inseticida sistêmico e maturadores ou inibidores.

As análises de sensibilidade para o custo horário com variação da área total da usina, da área a ser reformada, da área a ser tratada com inseticida sistêmico e do tempo total disponível para cada aplicação, demonstraram que a utilização de pulverizadores autopropelidos e aviões são as formas de pulverização que proporcionam menores custos horários obedecendo a todas as restrições. Como a aplicação de inseticida sistêmico só é feita com pulverizador autopropelido e as aplicações de maturados e inibidores com aviação agrícola, verifica-se que essas restrições foram as que mais afetaram o modelo.

O modelo de programação linear desenvolvido mostrou-se viável e eficaz para a seleção das diferentes formas de pulverização utilizadas na produção da cana-de-açúcar. Dessa forma, notase que o uso da programação linear na agricultura constituiu uma ferramenta importante para produtores e empresas, permitindo não somente otimizar, como identificar pontos críticos nos diferentes processos agrícolas.

\section{CONCLUSÔES}

- O modelo de programação linear inteira desenvolvido permitiu a otimização da funçãoobjetivo, auxiliando no processo de seleção das formas pulverização agrícola com base no menor custo horário;

- Para as áreas agrícolas da usina sucroalcooleira estudada, o valor da função-objetivo encontrado foi de $\mathrm{R} \$ 2.804,6 \mathrm{~h}^{-1}$. O custo por unidade de área para os conjuntos selecionados foi de $\mathrm{R} \$$ $29,99 \mathrm{ha}^{-1}$; e
- O modelo matemático desenvolvido facilitou a realização das análises de sensibilidade, sendo processadas em $11,97 \mathrm{~s}$, tempo considerado muito pequeno.

\section{REFERÊNCIAS BIBLIOGRÁFICAS}

ARAÚJO, E.C. Voando Alto. Revista Cultivar Máquinas, Pelotas, v.82, p.20-24, fevereiro 2009.

ASAE - Agricultural Machinery Management Data. ASAE Standards, Saint. Joseph, p.360-366, 1998.

BAIO, F.H.R.; ANTUNIASSI, U.R.; BALASTREIRE, L.A.; CAIXETA FILHO, J.V. Modelo de programação linear para seleção de pulverizadores agrícolas de barras. Revista Engenharia Agrícola, Jaboticabal, v.24, n.2, p.355-363, 2004.

BALASTREIRE, L.A. Máquinas agrícolas. Barueri: Editora Manole Ltda, 1990. 305p.

BALTIN, F. The Baltin formula. Agricultural Aviation 1, n.2, v.104, p.6, 1959.

BIEMBENGUT, M.S.; HEIN, N. Modelagem Matemática no Ensino. São Paulo. Editora Contexto. 2005. 128p.

CAIXETA FILHO, J.V. Pesquisa Operacional: Técnicas de Otimização Aplicadas a Sistemas Agroindustriais. São Paulo: Editora Atlas, 2004. 176p.

CALVAZARA, O. Planejamento da atividade agrícolana dinâmica da mudança. In: CONGRESSO 
BRASILEIRO DE SOJA, 1999, Londrina-PR. Anais... Londrina: Empresa Brasileira de Pesquisa Agropecuária - EMBRAPA, 1999. p.159-164.

FEY, E.; CATARINA, A.S.; SANTOS, S.R.; PEREIRA, J.O. Planejamento de um sistema agrícola utilizando programação linear: estudo de caso. Revista Engenharia Agrícola, Jaboticabal, v.22, n.3, p.368-77, 2002.

HOFFMANN, R.; ENGLER, J.J. de C.; SERRANO, O.; THAME, A.C. de M.; NEVES, E.M. Administração da empresa agrícola. 4. ed. rev. São Paulo: Pioneira, 1984. 325p.

MENEZES, A.H.; PINHEIRO, J.C.V.. Otimização da lavoura sob critérios múltiplos: uma proposta metodológica. In: XLII CONGRESSO DA SOCIEDADE BRASILEIRA DE ECONOMIA E SOCIOLOGIA RURAL, 2004, Cuiabá-MT, Anais... Dinâmicas Setoriais e Desenvolvimento Regional. Brasília-DF: SOBER, 2004. 15p.

MERCANTE, E.; SOUZA, E.G. de.; JOHANN, J.A.; G. FILHO, A.; URIBE-OPAZO, M.A. PRAPRAG - software para planejamento racional de máquinas agrícolas. Revista Engenharia Agrícola, Jaboticabal, v.30, n.2, p.322-333, 2010.

MIALHE, L.G. Manual de mecanização agrícola. São Paulo: Editora Ceres, 1974. 301p.

WILLIAMS, H.P. Model building in mathematical programming. 3. ed. Chichester: Wiley \& Sons, 1993. 353p. 